\title{
Neuro Model for Passive Suspension of a Light Car
}

\section{Dirman Hanafi ${ }^{1, *}$, Kian Sek Tee ${ }^{1}$, Elmy Johana ${ }^{1}$, Hisyam Abdul Rahman ${ }^{1}$, Mohd Fua'ad Rahmat ${ }^{2}$, Herman Wahid ${ }^{2}$, Rozaimi Ghazali ${ }^{3}$}

\author{
${ }^{1}$ Instrumentation and Sensing Technology (InSeT) Research Group, Faculty of Electrical and Electronic Engineering, \\ Universiti Tun Hussein Onn Malaysia, Batu Pahat, 86400, Johor, Malaysia. \\ ${ }^{2}$ Process Tomography \& Instrumentation Research Group (PROTOM-i), Faculty of Electrical Engineering, \\ Universiti Teknologi Malaysia, Johor, Malaysia. \\ ${ }^{3}$ Faculty of Electrical Engineering, Universiti Teknikal Malaysia Melaka, Melaka, Malaysia.
}

Received 28 February 2018; accepted 4 June 2018, available online 6 August 2018

\begin{abstract}
The system model is neccessery to be determined in control systems engineering which is generally represented in mathematical form. The mathematical model can be utilized for analysing the system's characteristics or designing the controller parameters of the system. The model should have a realistic dynamics and provides maximally informatives. With the ability of neural networks to model the non-linear and complex relationships between inputs and outputs of the system, therefore it is used to model the passive suspension system of light cars and it is called neuro models. The categories of the light cars here is a passenger car with five maximum number of passengers. The candidate structure of the neuro model is contructed from non-linear system of passive suspension of a quarter car mathematical model. Weights estimation of neuro model is conducted by applying iterative weighted least square algorithm. Actual input output data of a test car for training process are acquired by driving the test vehicle on an artificial surface of road. An artificial surface of road is a kind of real road surface imitation. Experimental findings show that the proposed model is able to imitate sucessfully the dynamic properties of the passive suspension system of the light car. The model response shows similar trend and has smallest error.
\end{abstract}

Keywords: Mathematical model, light car, passive suspension, neuro model, artificial road surface

\section{Introduction}

The suspension is an important component in a ground vehicle system. Generally, the suspension system has several types, they are classified as passive, semi-active, active and divers between systems [1-4]. Its physical features relate to the required energy and actuator characteristic frequencies [5]. The most common type is passive system, It uses several types of springs combined with hydraulic or pneumatic shock absorber $[3,4]$. There are several commonly used types of springs such as helices, leaves, coils, etc. Based on the spring type, various designs of passive suspension systems have been developed. This type only has the ability to store and dispose of energy in a predetermined manner. This will be a compromise between comfort factor, handling, and the suspension stroke over the range of operation $[1,2]$.

The handling of road, carrying of load and comfort of the passenger are three intention elements on the system of a car suspension. These requirements should be a compromise of all three factors to get a good system dynamics of a car suspension. To fulfill requirements, the suspension system should be analyzed and controlled comprehensively. For the car suspension system controller designing and analyzing, its realistc dynamic model is required.
The best strategy to prescribe the system model is applying system identification approach. The system identification method is a modelling technique that is needed for the interpretation of observations and measurements obtained from some systems of study [6,7]. As models constitute the necessary link between experiments and decision making (for example, prediction, learning new rules, and data compression), modeling and identification are very important for all applied science and engineering.

One of the major issues in system identification is a model structure to be the candidate model. Fidelity of a model formed via the method of the system identification is dependent on the formation of the candidate model that fits the dynamics of the real system. An artificial neural networks have many advantages, among others requiring less formal statistical training, capability to detect implicitly non-linear links between independent and dependent variables, capability to predict all possible interactions between predicted variables, and the availability of various training algorithms. Here, it is assumed that the car suspension system has a model as a quarter car model and has mathematical model structure as a neural network structure and it is called a neuro model.

Currently, the use of four independent suspensions in a car is a trend, therefore a quarter car system provides a 
quite rational for representing the real suspension system dynamics [2,8]. On most cases, a quarter car model offen uses for analysis of ride and the controller design of suspension [1,3-12].

\section{Neuro Model Approach}

In The passive suspension system uses several types of springs in the combination of pneumatic shock absorbers or hydraulic with the dynamic model as in Fig.1.

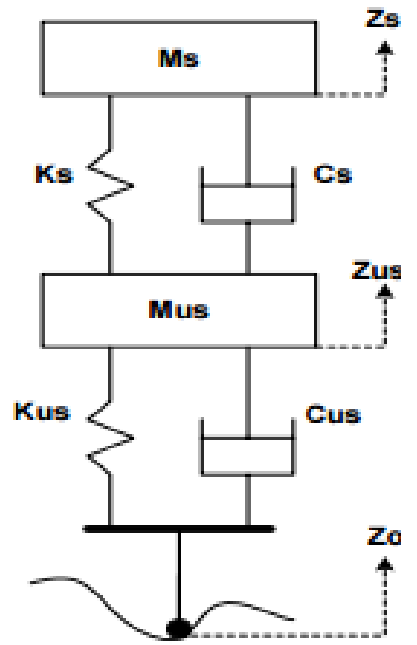

Fig. 1: Model of a quarter car system dynamics.

where $\mathrm{M}_{\mathrm{s}}$ is sprung mass, $\mathrm{M}_{\mathrm{us}}$ is unsprung mass, $\mathrm{Ks}$ is spring coefficient of suspension, Cs is damping coefficient of suspension, $\mathrm{K}_{\mathrm{us}}$ is coefficient of tire spring, $\mathrm{C}_{\mathrm{us}}$ is damping coefficient of tire, $Z_{s}$ is vertical displacement of sprung mass, $Z_{\mathrm{us}}$ is vertical displacement of unsprung mass and $\mathrm{Z}_{0}$ is elevation of road surface.

\section{Model of Tire}

The point contact type of tire model is used. This tire model type is compatible for car with few forces transmit from tires and identical composition. Type of a point contact tire model contains of spring stiffness and damping element as described in Fig. 2 [13]. The tire dynamic system is assumed linear and formulated as Eq.(1).

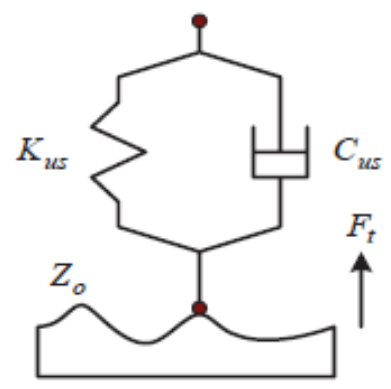

Fig. 2: Tire model for point contact type.

$F_{t}=C_{u s} \dot{Z}_{o}+K_{u s} Z_{o}$

where: $F_{t}$ is tire force, $C_{u s}$ is coefficient of the tire damping, $K_{u s}$ is coefficient of the tire spring stiffness and $Z_{O}$ is elevation of the road surface.

\section{Passive Suspension System Non-linear Dynamics}

For a non-linear spring, its stiffness can be broken up in to two parts as given by Fig.3 [13].

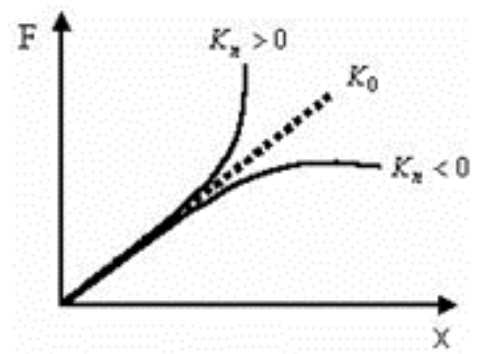

Fig.3. Coefficients of non-linear spring.

The coefficients of non-linear spring stiffness are presented by Eq.(2).

$K=K_{o}+K_{n} x$

where: $K_{o}$ is linear part, $K_{n}$ is non-linear part and function of $x$ and $x$ is displacement of the suspension.

The equation of nonlinear dynamic of spring is written down as the following:

$F=K x=\left(K_{o}+K_{n} x\right)=K_{o} x+K_{n} x^{2}$

The characteristics of non-linear damping is represents by Fig.4. It consists of linear and non-linear part as below:

$C=C+C_{n} \dot{x}$

where: $C_{o}$ is linear part, $C_{n}$ is non-linear part and function of velocity and $x$ is displacement of the suspension.

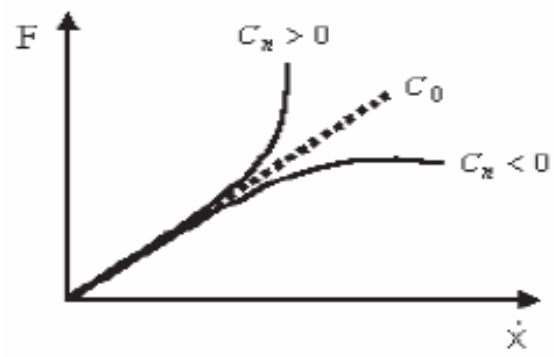

Fig.4. Coefficients of non-linear damping.

Non-linear force formula of the damper dynamics is as Eq.(5).

$F=C \dot{x}=\left(C_{o}+C_{n} \dot{x}\right) \dot{x}=C_{o} \dot{x}+C_{n} \dot{x}^{2}$

By using the second Law of Newton, linear models of a quarter car are as Eq.(6) and (7).

$$
\begin{aligned}
& M_{s} \ddot{Z}_{s}=-C_{s}\left(\dot{Z}_{s}-\dot{Z}_{u s}\right)-K_{s}\left(Z_{s}-Z_{u s}\right) \\
& M_{u s} \ddot{Z}_{u s}=C_{s}\left(\dot{Z}_{s}-\dot{Z}_{u s}\right)+K_{s}\left(Z_{s}-Z_{u s}\right)-C_{u s}\left(\dot{Z}_{u s}-\right. \\
& \left.Z_{o}\right)-K_{u s}\left(Z_{u s}-Z_{o}\right)
\end{aligned}
$$


Assumed $C_{S}$ and $K_{S}$ are non-linear as below:

$C_{s}=C_{s o}+C_{s n}\left(\dot{Z}_{s}-\dot{Z}_{u s}\right)$

$K_{s}=K_{s o}+K_{s n}\left(Z_{s}-Z_{u s}\right)$

The passive suspension system non-linear models of a quarter car are obtained by substituting Eq.(8) and (9) to Eq.( 6) and (7).

$$
\begin{aligned}
M_{s} \ddot{Z}_{s}=- & \left(C_{s o}+C_{s n}\left(\dot{Z}_{s}-\dot{Z}_{u s}\right)\right)\left(\dot{Z}_{s}-\dot{Z}_{u s}\right)- \\
& \left(K_{s o}+K_{s n}\left(Z_{s}-Z_{u s}\right)\right)\left(Z_{s}-Z_{u s}\right) \\
M_{u s} \ddot{Z}_{u s}= & \left(C_{s o}+C_{s n}\left(\dot{Z}_{s}-\dot{Z}_{u s}\right)\right)\left(\dot{Z}_{s}-\dot{Z}_{u s}\right)+ \\
& \left(K_{s o}+K_{s n}\left(Z_{s}-Z_{u s}\right)\right)\left(Z_{s}-Z_{u s}\right) \\
& -C_{u s}\left(\dot{Z}_{u s}-\dot{Z}_{o}\right)-K_{u s}\left(Z_{u s}-Z_{o}\right)
\end{aligned}
$$

In this case the suspension deflection is assumed to be as follows

$Y=Z_{s}-Z_{u s}$

Where $Z_{s}$ and $Z_{u s}$ are given by Eq.(13) and (14).

$$
\begin{gathered}
M_{s} \ddot{Z}_{s}=-\left(C_{s o}+C_{s n}\left(\dot{Z}_{s}-\dot{Z}_{u s}\right)\right)\left(\dot{Z}_{s}-\dot{Z}_{u s}\right)-\left(K_{s o}+\right. \\
\left.K_{s n}\left(Z_{s}-Z_{u s}\right)\right)\left(Z_{s}-Z_{u s}\right) \\
M_{s} \ddot{Z}_{s}=-K_{s o} Z_{s}+K_{s o} Z_{u s}-C_{s o}\left(\dot{Z}_{s}-\dot{Z}_{u s}\right)-K_{s n}\left(Z_{s}-\right. \\
\left.Z_{u s}\right)^{2}-C_{s n}\left(\dot{Z}_{s}-\dot{Z}_{u s}\right)^{2} \\
M_{s} \ddot{Z}_{s}=-K_{s o} Z_{s}+K_{s o} Z_{u s}-C_{s o}(\dot{Y})-C_{s n}(\dot{Y})^{2}+ \\
K_{s n}(Y)^{2} \\
\left.Z_{s}=-\frac{M_{s}}{K_{s o}} \ddot{Z}_{s}+Z_{u s}-\frac{C_{s o}}{K_{s o}}(\dot{Y})-\frac{C_{s n}}{K_{s o}}(\dot{Y})^{2}+\frac{K_{s n}}{K_{s o}}(Y)^{2}(13) \dot{Z}_{u s}\right)+ \\
M_{u s} \ddot{Z}_{u s}=\left(C_{s o}+C_{s n}\left(\dot{Z}_{s}-\dot{Z}_{u s}\right)\right)\left(\dot{Z}_{s}-\dot{Z}_{u s}\right)+ \\
\quad\left(K_{s o}+K_{s n}\left(Z_{s}-Z_{u s}\right)\right)\left(Z_{s}-Z_{u s}\right) \\
\quad-C_{u s}\left(\dot{Z}_{u s}-\dot{Z}_{o}\right)-K_{u s}\left(Z_{u s}-Z_{o}\right) \\
M_{u s} \ddot{Z}_{u s}=C_{s o}\left(\dot{Z}_{s}-\dot{Z}_{u s}\right)+C_{s n}\left(\dot{Z}_{s}-\dot{Z}_{u s}\right)^{2}+ \\
\quad K_{s o}\left(Z_{s}-Z_{u s}\right)+K_{s n}\left(Z_{s}-Z_{u s}\right)^{2} \\
\quad-C_{u s} \dot{Z}_{u s}+C_{u s} \dot{Z}_{o}-K_{u s} Z_{u s}+K_{u s} Z_{o} \\
Z_{u s}=-\frac{M_{u s}}{K_{u s}} \ddot{Z}_{u s}-\frac{C_{u s}}{K_{u s}} \dot{Z}_{u s}-\frac{C_{u o}}{K_{u s}}(\dot{Y})+\frac{C_{s n}}{K_{u s}}(\dot{Y})^{2}+ \\
\frac{K_{s o}}{K_{u s}}(Y)+\frac{K_{s n}}{K_{u s}}(Y)^{2}+\frac{C_{u s}}{K_{u s}} \dot{Z}_{o}+Z_{o}
\end{gathered}
$$

Function $f$ is a sigmoidal function, a well known and most commonly used as a neuron activation in neural network application and also applied in this work.

$f(n e t)=\frac{1}{1+e^{-n e t}}$

and

$n e t_{1}=w_{11} \ddot{Z}_{s}+w_{12} Z_{u s}+w_{13} \dot{Y}+w_{14} \dot{Y}^{2}+w_{15} Y^{2}$

$$
\begin{aligned}
\text { net }_{2}= & \ddot{Z}_{u s}+w_{22} \dot{Z}_{u s}+w_{23} \dot{Y}+w_{24} \dot{Y}^{2}+w_{25} Y+ \\
& w_{26} Y^{2}+w_{27} \dot{Z}_{o}+w_{28} Z_{o} \\
\text { net }_{y}= & w_{y 1} Z_{s}+w_{y 2} Z_{u s}
\end{aligned}
$$

Then the position of sprung mass, unsprung mass and deflection of the suspension of a quarter car passive suspension system neuro models [13] are shown by Eq.(19), (20) and (21) respectively.

$Z_{s}\left(\right.$ net $\left._{1}\right)=f\left(\right.$ net $\left._{1}\right)$

$Z_{\text {us }}\left(\right.$ net $\left._{2}\right)=f\left(\right.$ net $\left._{2}\right)$

$Y\left(\right.$ net $\left._{y}\right)=f\left(\right.$ net $\left._{y}\right)$

Based on previous mathematical models a network can be formed as shown by Fig.5.

\section{Algorithm of Unitwise Iterative Weighted Least Squares}

The Fisher information associated to the weights of the input layer to the hidden layer is as below [7]:

$$
\begin{aligned}
F_{w_{j}}= & \sum_{p=1}^{P} x_{p l} \delta_{p k}\left(1-2 y_{p k}\right) \chi_{p m j} \vartheta_{p j} \vartheta_{p m} x_{p i}- \\
& \sum_{p=1}^{P} x_{p l} \Omega_{p k}\left(1-2 y_{p k}\right) \chi_{p m j} \vartheta_{p j} \vartheta_{p m} x_{p i}= \\
& X^{T} Q_{w_{j}} X
\end{aligned}
$$

Where,

$Q_{w_{j}}=\operatorname{diag}\left(\left(\delta_{p k}\left(1-2 y_{p k}\right)-\omega_{p k} \Omega_{p k}\right) \vartheta_{p j} \chi_{p i j} \vartheta_{p j}\right.$ and $j$ is the number of hidden neuron. This equation is an input vectors weighted covariance matrix. The weighted least squares estimation normal equation for obtaining the current estimates of the weights $W_{w_{j}}^{*}$ is as the following

$X^{T} Q_{w_{j}} X W_{w_{j}}^{*}=X^{T} Q_{w_{j}}\left(\varsigma_{j}+Q_{w_{j}}^{-1} \delta_{w_{j}}\right)$

Where,

$\delta_{w_{j}}=\left(\sum_{k=1}^{K} \omega_{1 k} \delta_{1 j} v_{1 j}, \cdots, \sum_{k=1}^{K} \omega_{P k} \delta_{P j} v_{P j}\right)$

$\varsigma_{j}=\left(\varsigma_{j 1}, \cdots, \varsigma_{j P}\right)^{T}$

Likeness, Fisher's information for output layer weights and related to normal equation are formulated as:

$F_{v_{k}}=\left(Z_{p m} \delta_{P k}\left(1-2 y_{p k}\right) \omega_{P k} Z_{p j}\right)=Z^{T} Q_{v_{k}} Z$

and

$Z^{T} Q_{v_{k}} Z V_{v_{k}}^{*}=Z^{T} Q_{v_{k}}\left(\eta_{k}+Q_{v_{k}}^{-1} \delta_{v_{k}}\right)$

Where,

$Z^{T}=\left(Z_{1}, Z_{2}, \cdots, Z_{P}\right)$

$Q_{v_{k}}=\operatorname{diag}\left(\left(\delta_{p k}\left(1-2 y_{p k}\right) \omega_{p k}\right.\right.$ 
$\eta_{k}=\left(\eta_{1 k}, \cdots, \eta_{P k}\right)$

$\delta_{v_{k}}=\left(\delta_{1_{k}} \omega_{1 k}, \cdots, \delta_{P_{k}} \omega_{P k}\right)^{T}$

The estimates $\quad\left\{W_{w_{j}} \mid j=1,2, \cdots, J\right\}$

$\left\{V_{v_{k}} \mid k=1,2, \cdots, K\right\}$ are frequently renew through solving normal equation. This method is named is Unitwise Fisher's scoring method [13]. Each neuron weights as a unit of the networks is estimated through iterative weighted least squares algorithm. After that, these normal equations will solve using weighted least squares recursive formulas. This shows the relationship between the Unitwise Fisher Scoring algorithm and the backpropagation learning algorithm.

The optimal parameter values related to the previous learning sample set and the new learning sample are given as below

$W_{w_{j}}^{N}=W_{w_{j}}^{N-1}+R_{w_{j}}^{N} x_{N} \omega_{N} \sigma_{N j} v_{N j}$

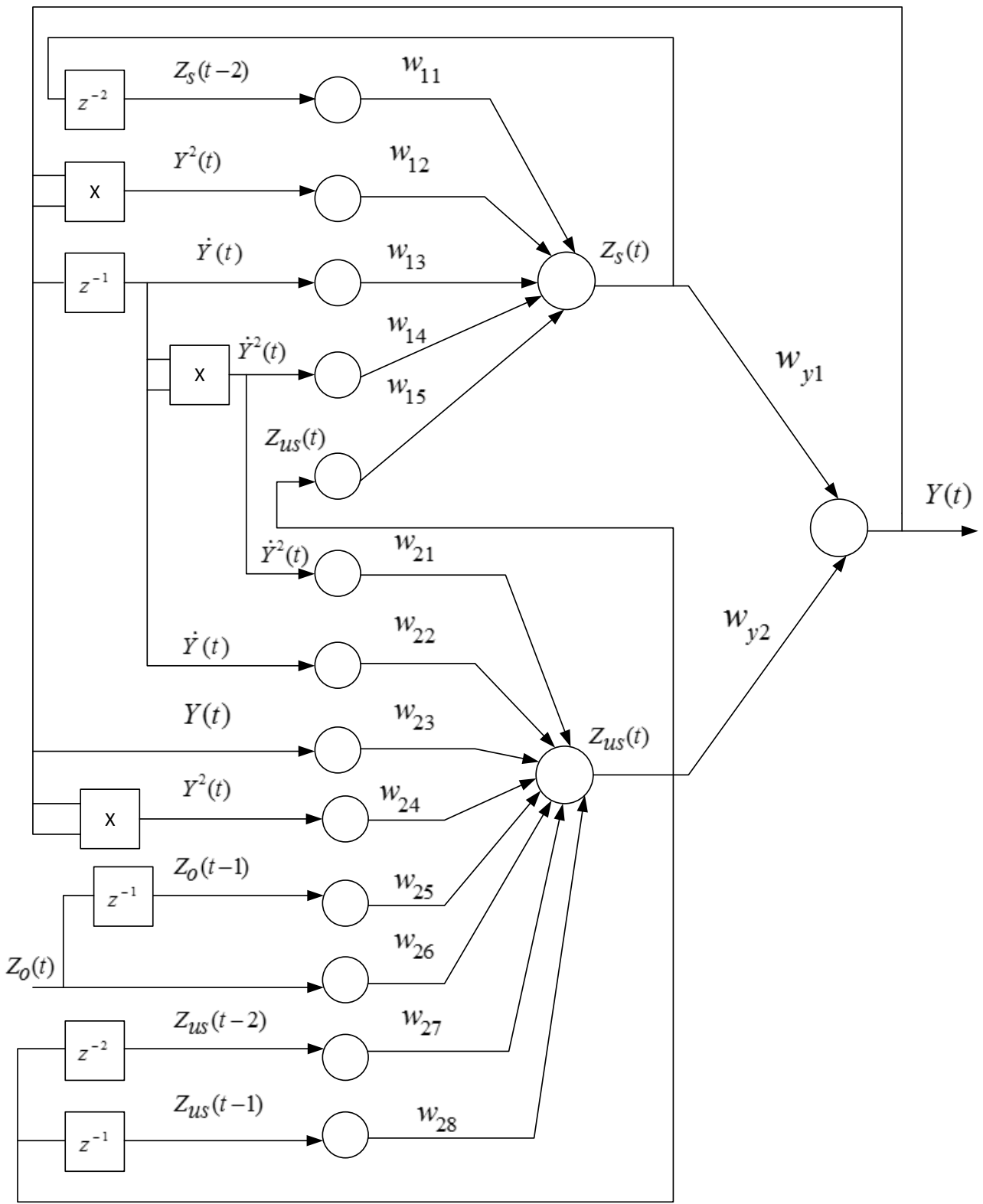

Fig.5. Neuro model of a quarter car.

Where, the matrix $R_{w_{j}}^{N}$ is the inverse of the weighted covariance matrix $X^{T} Q_{w_{j}} X$ with its recursive formula is given by
$R_{w_{j}}^{N}=R_{w_{j}}^{N-1}-\frac{\left(\delta_{N}\left(1-2 y_{N}\right)-\omega_{N} \Omega_{N}\right) v_{N j} \chi_{N j} v_{N j} R_{w_{j}}^{N-1} X_{N} X_{N}^{T} R_{w_{j}}^{N-1}}{1+\left(\delta_{N}\left(1-2 y_{N}\right)-\omega_{N} \Omega_{N}\right) v_{N j} \chi_{N j} v_{N j} X_{N} R_{w_{j}}^{N-1} X_{N}^{T}}$

In the same manner, the recursive formula for $v_{v_{k}}$ is given by 
$v_{v_{k}}^{N}=v_{v_{k}}^{N-1}+R_{v_{k}}^{N} x Z_{N} \delta_{N k} \omega_{N k}$

$R_{v_{k}}^{N}=R_{v_{k}}^{N-1}-\frac{\delta_{N}\left(1-2 y_{p k}\right) \omega_{N k} R_{v_{k}}^{N-1} Z_{N} Z_{N}^{T} R_{v_{k}}^{N-1}}{1+\delta_{N}\left(1-2 y_{p k}\right) \omega_{N k} Z_{N}^{T} R_{v_{k}}^{N-1} Z_{N}}$

\section{Data Collection}

The accuracy and the representation of experimental data depend on data acquisition hardware, sensor, and experimental procedure $[6,7,13]$. In this research, Arduino mega is used as data acquisition hardware. Because it has several advantages, among others it has additional I / $\mathrm{O}$ and serial ports and abundant code space, so it can be used as data acquisition hardware. Besides its price is cheap and also easy to get compared to usual data acquisition hardware. The purpose of the data acquisition system is to serve the data logging and data analysis of the measurement results. Therefore, the data acquisition system is an instrument that it has the capability for measuring some parameters. This system is generally electronics based and it is a combination of hardware and software. The hardware parts consist of sensors, cables and electronic components. Meanwhile, the software parts consist of the analysis software and other utilities that can be used to configure the logic or to transfer data from data acquisition to laptop or desktop computer. In this research, data logging is carried out by the data acquisition, it is used to measure the displacement and the acceleration of the car body.

But before any mathematical model estimation are derived, it is necessary to design the experimental procedure carefully. Also in order to minimize measurement noise, it is essential to choose wisely the data acquisition hardware and software, and the sensor system. The input of the system must be able to completely explore the system dynamics.

In order to produce a high fidelity of a quarter car passive suspension mathematical model, we need several requirements as below [13]:

- Data are collect in an experimental way.

- Input variable is an artificial road surface with known parameters to imitate a real road surface.

- Sprung mass and unsprung mass vertical acceleration data are measured using accelerometer sensor.

- Data are acquired by driving a test car on the artificial road surface.

\section{Sensor Installation}

The assumptions used in a quarter car model, where its dynamics are same for the four sides. So to analyze its dynamics can be done on one side only. In this work is taken is the left front side, because it is easy for getting data acquisition power source and installing process. Besides, there is also enough space to facilitate the sensors installation.

Three data required in this study, they are the vertical acceleration of the car body, the vertical acceleration of the axle and the suspension displacement. The car's body and axle acceleration data are measured using acceleration sensor, while the suspension displacement is measured using LVDT sensor.

The car's body vertical acceleration is measured by mounted an accelerometer sensor on the car body at top of suspension as shows in Fig. 6(a). The axle or the unsprung mass vertical acceleration is measured by mounted an accelerometer sensor on the lower arm at the bottom of the suspension of the test car as illustrate in Fig. 6(b). One LVDT sensor is used to measure the car suspension displacement and installed between the top and bottom of the suspension as illustrated in Fig. 6(c).

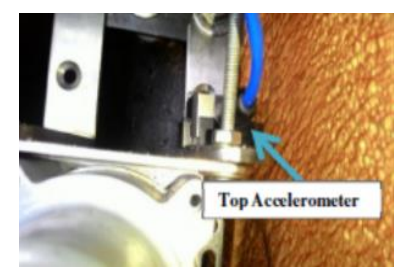

(a)

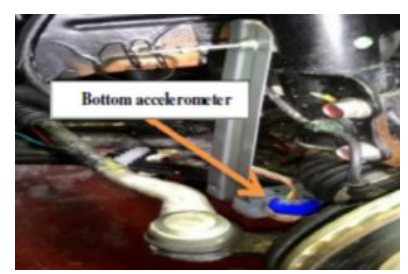

(b)

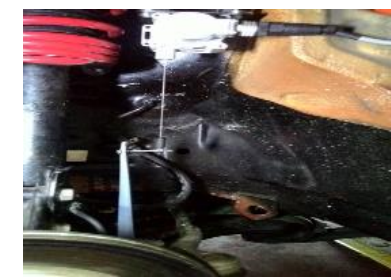

(c)

Fig.6: The accelerometers sensors and the displacement sensor installation.

\section{Artificial Road Surface}

Input and output data of a car suspension system are collected by driving a test car on artificial road surface to investigate the vehicle suspension dynamic [13-14]. The road surface types are designed using plywood and the beam is made from wood in which is called an artificial road surface. The artificial road surfaces have known parameters therefore it is easy to convert into a signal form. The artificial road surface is a known parameters road surface imitation as shown in Fig. 7. The parameters consist of width and height of beam, distance between one beam into another and total length of road surface. 


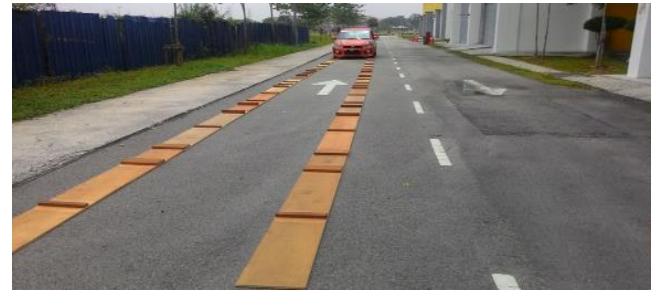

Fig. 7: The artificial road surface and experimental enviroment.

A light passenger car is choosen as an object in this research. A light passenger car means a passenger car with five maximum number of passengers. Sometimes also categories as cars with engine capacity of less than 2.5 liters. The test car specification is elaborated in Table 1.

Table 1. Specification of the test car

\begin{tabular}{|l|l|}
\hline Mark & Myvi 1.3 Manual \\
\hline Year & 2012 \\
\hline Front suspension type & $\begin{array}{l}\text { MacPherson Strut \& Coil } \\
\text { Spring }\end{array}$ \\
\hline Rear suspension type & Multilink \& Coil Spring \\
\hline $\begin{array}{l}\text { Weight (+2 passenger } \\
\text { and DAS) }\end{array}$ & $980 \mathrm{~kg}+120 \mathrm{~kg}+3 \mathrm{~kg}$ \\
\hline Front tire pressure & $22 \mathrm{psi}$ \\
\hline Rear tire pressure & $20 \mathrm{psi}$ \\
\hline Car speed & $10 \mathrm{~km} / \mathrm{h}$ and $20 \mathrm{~km} / \mathrm{h}$ \\
\hline
\end{tabular}

\section{Experimental Results and Analysis}

In this experimental the input variables are an artificial road surface with known parameters [13]. By considering the time sampling, the artificial road surface as in Fig. 7 is converted into the signal form. The amplitude of the road surface is in meter (m) and the length of the time conducted the experiment in second (s). Fig. 8 shows the signal form of the road surface imitation or artificial road surface.

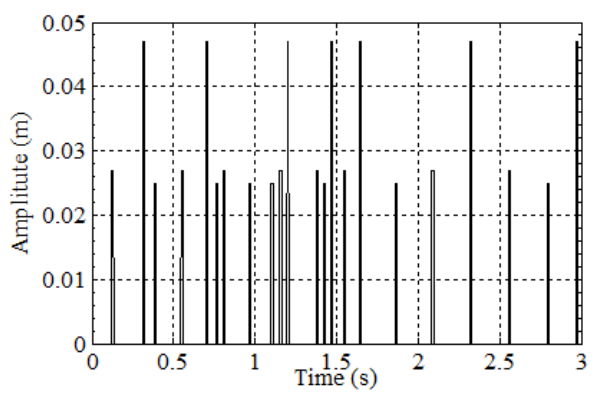

Fig. 8: Artificial road surface signal.

For input output data collection, three sensors are used in this experimental work. There are deflection sensor to measure suspension deflection and two acceleration sensors for measuring car body (sprung mass) vertical accelaration and axle (unsprung mass) vertical acceleration respectively. The output signals are as below:

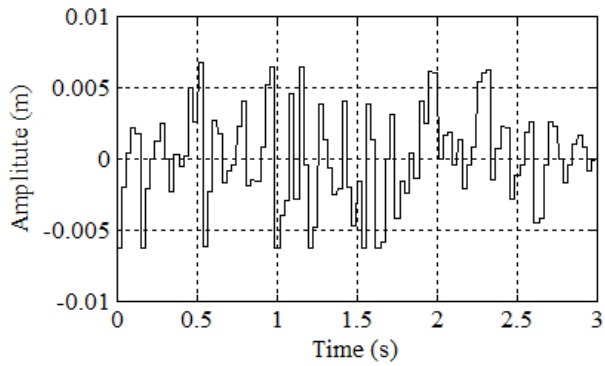

Fig. 9. Suspension deflection signal.

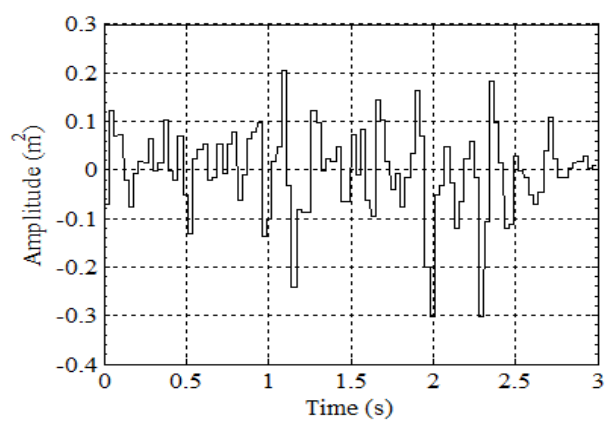

Fig. 10. Sprung mass vertical acceleration signal.

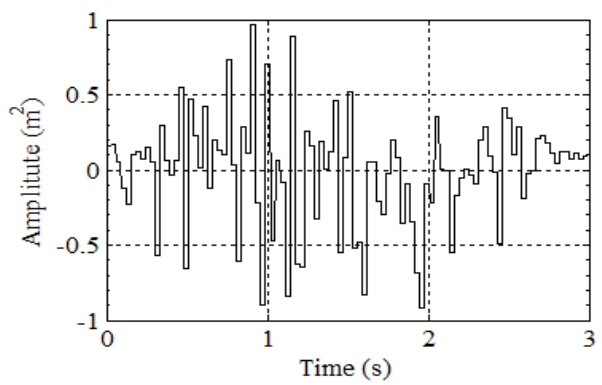

Fig. 11. Vertical acceleration signal of unsprung mass.

Using previous data, the neuro model for passive suspension system dynamic of a quarter car is identified. The comparison between the system response and the identified model response is represented by Fig. 12 .

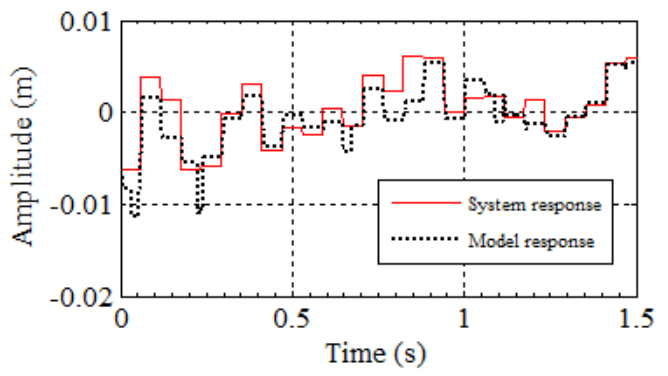

Fig.12. Comparison between the system response and neuro model response.

The best neuro model is given by the MSE values, the residual autocorrelation and the residual cross correlation graphs as below: 


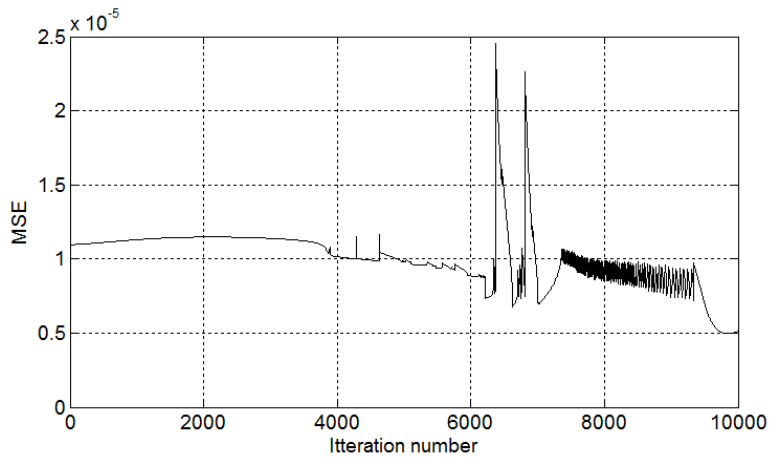

Fig. 13. Mean Square Error.

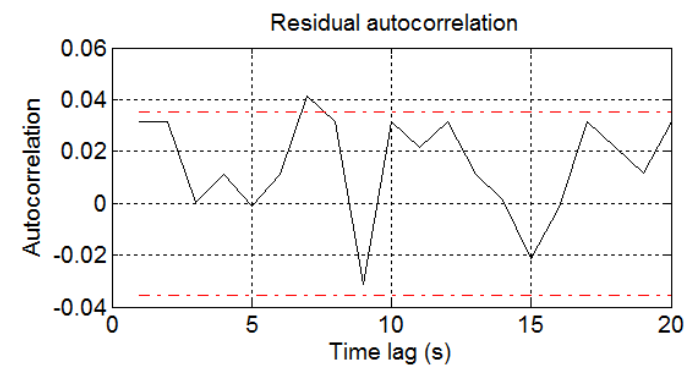

Fig. 14. Residual autocorrelation.

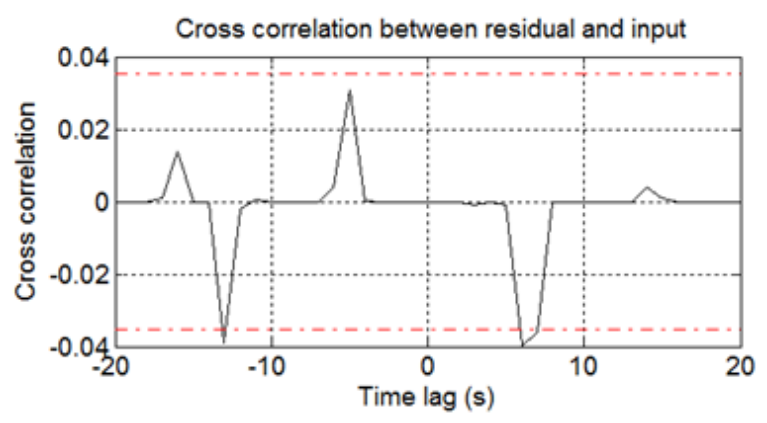

Fig. 15. Residual cross correlation.

The best neuro model for passive suspension system dynamic of a quarter car has achieved as represented by Eq.(36) till Eq.(42).

$$
\begin{aligned}
n e t_{1}= & 0.0033 \dot{Z}_{s}-0.0027 \ddot{Z}_{s}-0.0291 \dddot{Z}_{s}- \\
& 0.0296 \dot{Z}_{u s}-0.1250 \ddot{Z}_{u s}-0.1216 \dddot{Z}_{u s}- \\
& 0.1186 \dot{Y}-0.0301 \ddot{Y}-0.0301 \dot{Y}^{2}-0.0301 \ddot{Y}^{2}
\end{aligned}
$$

$$
\begin{aligned}
n e t_{2}= & -0.0914 \dot{Z}_{u s}-0.1216 \ddot{Z}_{u s}-0.1206 \dot{Y}- \\
& 0.1197 \ddot{Y}-0.0918 \dot{Y}^{2} 0.0918 \ddot{Y}^{2}-0.0918 \dot{Z}_{o}- \\
& 0.1027 \ddot{Z}_{o}
\end{aligned}
$$

net $_{y}=-5.8687 Z_{s}-1.7692 Z_{u s}$

$Z_{s}\left(n e t_{1}\right)=f\left(\right.$ net $\left._{1}\right)$

$Z_{\text {us }}\left(\right.$ net $\left._{2}\right)=f\left(\right.$ net $\left._{2}\right)$

$Y\left(\right.$ net $\left._{y}\right)=f\left(\right.$ net $\left._{y}\right)$

$f(n e t)=\frac{e^{c * n e t}}{1+e^{c * n e t}}-0.5$
This model has almost identical trend with the system response. Autocorrelation and cross correlation between residual and input are rested in confident limit as described in Fig. 14 and 15 respectively.

\section{Summary}

The best neuro model for passive suspension system dynamic of a quarter car from system identification has sprung mass variable, unsprung mass variable, deflection of the suspension (output) variable, road surface (input) variable orde, and road surface variable delay time powers are 3, 3, 2, 1 and 2 respectively. This model has similar trend with the system response. Autocorrelation and cross correlation between residual and input are laid in confident limit respectively. Beside that, this model also gives minimum $\mathrm{MSE}=4.9682 \mathrm{e}-006$, lowest value Final prediction error criterion $(\mathrm{FPE})=1.0007 \mathrm{e}-016$ and loss_function $=5.1072 \mathrm{e}-006$. Its statistical autocorrelation residual $\left(r_{e e}\right)=6.0868$ and statistical cross correlation between residual and input $\left(r_{e u}\right)=4.0437$ are fulfilled the criteria for limit interval 20 with $99 \%$ confident limit, $r_{e e}$ and $r_{e u}$ must less than 37.6.

\section{Acknowledgment}

This research was funded by Research Management Center (RMC) of Universiti Tun Hussein Onn Malaysia under RACE grant with vot. no. 1439.

\section{References}

[1]. Raju, A.B., and Venkatachalam, R. Analysis of Vibrations of Automobile Suspension System Using Full-car Model. International Journal of Scientific \& Engineering Research, 4(9), (2013), pp. 2105-2111.

[2]. Bosch, R. Automotive Handbook. Society of Automotive Engineers (SAE), Inc., 400 Commonwealth Drive, Warrendale, (2002).

[3]. Jin, X.J., Yin, G., Zhang, N., and Chen, J. Improving vehicle handling stability performance via integrated control of active front steering and suspension systems. Procceeding of IEEE Conference and Expo Transportation Electrification Asia-Pacific (ITEC Asia-Pacific 2016), (2016), pp. 621-625.

[4]. Moghadam-Fard, H., and Samadi, F. Active Suspension System Control Using Adaptive NeuroFuzzy (ANFIS) Controller. International Journal Engineering Transaction C: Aspects, 28(3) (2015), pp. 396-401.

[5]. Wang, G., Chen, C., and Yu, S. Finite-time sliding mode tracking control for active suspension systems via extended super-twisting observer. Procceeding of the Institution of Mechanical Engineers, Part I: Journal of Systems and Control Engineering, 231(6), (2017), pp. 459-470.

[6]. Tangirala, A.K. Principles of System Identification: Theory and Practice. CRC Press, (2014).

[7]. Allmaras, M., Bangerth, W., Linhart, J.M., Polanco, J., Wang, F., Wang, K., Webster, J., and Zedler, S. Estimating Parameters in Physical Models through 
Bayesian Inversion: A Complete Example. SIAM Review, 55(1), (2013), pp. 149-167.

[8]. Ersal, T., Kittirungsi, B., Fathy, H.K., and Stein, J.L. Model Reduction in Vehicle Dynamics Using Importance Analysis. Procceeding of ASME Dynamic Systems and Control Conference, (2008), pp. 1-8.

[9]. Patil, A.R., and Sawant, S.H. Numerical and Experimental Ride Comfort Analysis of Quarter Car Model Active Suspension System Subjected to Different Road Excitations with Nonlinear Parameters. International Journal of Advanced Information Science and Technology (IJAIST), 4(12), (2015), pp. 102-107.

[10]. M.Sever and H.Yazici. Disturbance Observer Based Optimal Controller Design for Active Suspension Systems. Procceeding of $6^{\text {th }}$ IFAC Symposium on System Structure and Control (SSSC 2016), (2016), pp. 105-110.

[11]. Sathishkumar, P., Jancirani, J., John, D., and Manikandan, D. Mathematical modeling and simulation quarter car vehicle suspension. International Journal of Innovative Research in Science, Engineering and Technology, 3(1), (2014), pp. 1280-1283.

[12]. Jazar, R.N. Vehicle Dynamics: Theory and Application. 3rd Edition, Springer, (2017).

[13]. Hanafi, D. Neural Network System Identification: Experimental Approach of a Quarter Car Modelling. UTHM Publisher, (2012).

[14]. Kasprzyk, J., Kauze, P., Budzan, S., and Rzepecki, J. Vibration control in semi-active suspension of the experimental off-road vehicle using information about suspension deflection. Archives of Control Sciences, 27(LXIII), (2017), pp. 251-261.

[15]. Agharkakli, A., Chavan, U.S., and Phvithran, S. Simulation And Analysis Of Passive And Active Suspension System Using Quarter Car Model For Non Uniform Road Profile. International Journal of Engineering Research and Applications, 2(5), (2012), pp. 900-906. 